\title{
Teaching Chinese to International Students in China: Political Rhetoric and Ground Realities
}

\author{
Weihong Wang ${ }^{1} \cdot$ Xiao Lan Curdt-Christiansen ${ }^{2}$ (1)
}

Published online: 30 September 2016

(C) The Author(s) 2016. This article is published with open access at Springerlink.com

\begin{abstract}
This paper presents an on-going study of the enactment of The International Promotion of Chinese Policy (国际汉语推广政策). It explores how Chinese teaching and learning take place in a Chinese university under the Study in China Programme which allows international students, after a period of intensive Chinese language learning, to transfer to academic courses taught in Chinese for Chinese students at the tertiary level. This programme has expanded in recent years in response to the government's goal to enhance China's soft power globally. By studying policy documents, engaging in conversations with students and teachers and observing classrooms, our study reveals that there are conflicting interests of social actors at national, institutional and individual levels, causing considerable conflicts and tensions in three aspects: (1) the divergent goals of internationalisation between the government and the higher education institution; (2) the imperative need of academic Chinese for subject learning and the actual offer of Chinese for everyday communication and (3) the competing role of English versus Chinese as a lingua franca for international students in the university setting. These conflicts make it difficult for international students to benefit from the subject courses, and for universities to implement successful language programmes for international students, and this
\end{abstract}

Xiao Lan Curdt-Christiansen

x.1.curdt-christiansen@ reading.ac.uk

Weihong Wang

wangwhw@connect.hku.hk

1 School of Foreign Studies, China University of Geosciences, Wuhan 430074, Hubei, China

2 Institute of Education, University of Reading, 4 Redlands Road, Reading, Berkshire RG1 5EX, UK renders the political objective of this programme difficult to achieve.

Keywords International students - Study in China • The International Promotion of Chinese Policy

\section{Introduction}

Chinese globalisation has been the topic of much scholarly work in the recent years (Fallon 2014; Tsung and Cruickshank 2011). Indeed, China's intensified effort to popularise Chinese (Putonghua mainly) in the last few decades has yielded some daunting statistics, in particular, with two Chinese promotion programmes-Confucius Institutes (CIs) and The Study in China Programme (SiCP). In this study, we focus on The Study in China Programme. As an internal promotion programme, $\mathrm{SiCP}$ has been established to attract international students to study in China (MOE 2010a, b). Connected with China's broader foreign policy goals, the SiCP allows international students, after a period (1 or 2 years) of intensive Chinese language learning, to transfer to academic courses taught in Chinese at the tertiary level. According to the Ministry of Education, the number of international students studying in China has risen sharply in the recent years and the number reached 397,635 in 2015 (MOE 2016).

The massive language outreach together with the rise of China's economy has led the outside world to suspect an underlying political agenda (Paradise 2009). Some scholars believe that China is on the rise to become a global power and that Chinese is to replace English as the lingua franca for international communication (Fallon 2014). Others speculate that a new world order deviating from the Eurocentric or Western-based world system is taking shape with China 
playing a very central role (Schweller and $\mathrm{Pu}$ 2011). These speculations, however, provided little evidence on what these International Promotion of Chinese programmes (国际汉语推广政策) offer and how they have been carried out across different socio-political contexts. In particular, how $\mathrm{SiCP}$ as an important tool in China's public diplomacy communicates its objectives through international students. Our study attempts to fill the gap by focusing on these international students under the SiCP. Using an ethnographic case study design, we choose one Chinese university as an illustrative case to examine how the $\mathrm{SiCP}$, as a means of Promoting Chinese Policy, is implemented in China.

\section{Chinese Promotion Policy and International Student Education in China}

Promoting Chinese through the education of international students (the $\mathrm{SiCP}$ ) has been an important 'image' planning policy of China. Ever since the establishment of the new China in 1949, it had been appropriated by the government to develop international relationships with other friendly nations (Cui 2010). The focus of the programme was on Chinese language and the literature studies and only a few government-endorsed universities were allowed to offer the programme. Therefore, the development of the programme at that time was rather slow with only 12,800 students from nations in East Europe, Asia and Africa having joined the programme by 1978 (Cui 2010).

Since 1978 the economic reform and the open-door policy have led to a gradual increase of international students in China, but a real boost of the programme occurred in the twenty-first century due to favourable conditions in and outside of China. Internationally, the economic prosperity and rising influence of China have strengthened the appeal of the Chinese language to the outside world. Accordingly, Chinese has been increasingly considered as a language of instrumental value which can provide jobs or business opportunities and enable greater international mobilities. Thus, a Chinese fever has been sweeping over the world and bringing with it a sharp rise of Chinese learners in many countries around the world (Curdt-Christiansen and Hancock 2014; Tsung and Cruickshank 2011). Domestically, the Chinese government sees the teaching of Chinese as a crucial means to promote Chinese culture and enhance the international understanding of China as a nation, a point explicitly expressed on the webpage of the Chinese Government Scholarships (CSC 2015):

In order to promote the mutual understanding, cooperation and exchanges in various fields between China and other countries, the Chinese government has set up a series of scholarship programmes to sponsor international students, teachers and scholars to study and conduct research in Chinese universities.

With the purpose to promote "mutual understanding, cooperation and exchanges", the government has greatly scaled up the offers of Chinese Government Scholarships to international students. Along with this policy, universities view international student education as an opportunity to acquire a diverse student population, thus promoting the image of internationalisation of Chinese higher education. In 2010, the government has promulgated the Outline of China's National Plan for Medium and Long-term Education Reform and Development (2010-2020). It recognises "education internationalisation" as a major mission for Chinese universities (MOE 2010a). In response to the Outline, a Study in China Plan was launched soon after (MOE 2010b), which explicitly makes "increasing the number of international students in China to 500,000 by 2020" and "making China the Top 1 destination in Asia for students to study abroad" a task of Chinese universities (MOE 2010b). Against this backdrop, the number of international students has increased sharply to 397,635 by 2015 and the demographic profiles have also greatly diversified, covering 203 countries. Moreover, the education programmes have expanded to include both academic diplomas (BA, MA or $\mathrm{PhD}$ ) and non-academic degrees (language courses and visiting programmes).

While the promotion of Chinese has achieved its goal regarding the number of international students, there is a dearth of research into how universities deal with the challenges and needs of this diversified student population. Among the few studies available, Dong and Chapman (2008) surveyed 270 scholarship recipients and found that the Government Scholarship was an effective way to spread goodwill for China and build up international relationship. Haugen's (2013) study on African students in Guangdong and Zhejiang, however, pointed out that low tuition fees and the availability of scholarships were important appeals for African students, but the pervasive discontent with the education they received in China impeded China's vision to enhance its soft power through attracting international students to study in China. Li's (2015) case study on five international students revealed that individual factors such as their sense of belonging, engagement with the host culture, and the power of their mother tongues also contributed to different learning experiences in China.

In sum, these studies point to the complexities of language spreading through international student education. To gain an in-depth understanding of the various factors involved in the $\mathrm{SiCP}$, we situated our study in a Chinese university to examine how the programme was enacted in the local context. 


\section{Methodology}

\section{Research Design}

Our study adopts an "ethnography of language policy" (Johnson 2013) design to investigate how internal Spreading Chinese is promoted through the $\mathrm{SiCP}$ at a state university in China. Ethnography of language policy offers both a theoretical and a methodological framework "for examining the agents, contexts, and processes across the multiple layers of language policy creation, interpretation, and appropriation" (Johnson 2013, p. 44). As a theory, it encompasses various types of language planning activities from status to acquisition, and various levels of language policy appropriations from macro to micro. As a methodological framework, it emphasises that language policies are driven by ideologies that can be conflictual. As such, research should focus on how "human agents engage with LPP processes" by taking into consideration the agents (the creators of the policy and those responsible for policy interpretation and appropriation), goals (the intentions of the policy as stated in the policy text), processes (the creation, interpretation and appropriation), discourses (the discourses within the policy texts and also with relation to other policies), and contexts (the dynamic social, historical, and physical contexts) (Johnson 2013, p. 145).

\section{The Site}

The study took place in one of the key 211 Project $^{1}$ universities in China (hereafter UoX) located in a provincial capital in central China. UoX is a comprehensive university, consisting of 19 faculties that offer various disciplines, including 67 undergraduate, 81 master and 35 doctoral programmes. Currently, it has a total enrolment of more than 25,500 full-time students, of whom 800 are international students who are in the charge of the International Education College (IEC), a designated institute responsible for the foreign affairs of UoX. The college is also in charge of international student recruitment, enrolment, accommodation and Chinese language education. At the time of our investigation, there were nearly 200 exchange students and 667 registered international students from over 50 countries and regions. Among them, 410 were from Africa and 182 from Asia. 443 were government scholarship recipients and 224 self-funded. As to the programmes, only 56 were registered for non-degree programmes, and the remaining $611(91.6 \%)$ pursued various degrees with 214 for BA, 299 for MA and 98 for doctoral programmes.

\footnotetext{
${ }^{1}$ Project 211 is a Chinese government project initiated in 1995 to strengthen about 100 Chinese universities or $6 \%$ of the over 1700 standard higher education institutions in China.
}

These students are housed together in a building specially allocated to them and separated from student dormitories for the local Chinese students. Conventionally, Chinese students are accommodated collectively in student halls which are shared based on disciplines and registration years. All student halls are concentrated in a few areas on campus. But the international student building is situated away from the student halls. Consequently, international students form their own community without much interaction with Chinese students in everyday life.

\section{Participants}

The participants involved in this study were three groups of policy actors: three administrators responsible for SiCP; five Chinese language lecturers (CLL-T1-5) and three disciplinary subject lecturers (DSL-T1-3); six Chinese language students (CLL-S1-6) and eight disciplinary subject students (DSL-S1-8). Recruited through purposeful and convenient sampling, these policy actors provide important insight into how language policy is engaged at macro-level, interpreted at meso-level and appropriated at micro-level.

\section{Data Collection and Analysis}

The study was conducted over 6 months (Sept. 2014 to Mar. 2015). Following the principles of language policy ethnography, empirical data were collected from multiple sources with the approval of IEC and all participants involved: (1) documentary data about international student education, stated on web pages, curricula, and policies at both institutional and national levels; (2) participant observation of 24 sessions of Chinese language preparatory courses and 8 sessions of subject courses; (3) detailed field notes and (4) semi-structured interviews with three levels of policy actors (See Appendices I and II for information of the observed courses and the interview participants).

The data were then repeatedly read, triangulated and coded. In line with the analytical framework of language policy ethnography to examine "the agents, contexts, and processes across the multiple layers of language policy creation, interpretation, and appropriation" (Johnson 2013, p. 44), the coding was developed into four categories: context (the macro-discourse at the national level), setting (the immediate environment at the institutional level), situated activity (interactions in specific learning situations) and self (the individual student's personal experiences and self-conceptualisation). Using discourse analysis broadly, we compared and contrasted the categorisations to generate connections within and across the categories and uncover potential conflicts or mismatches in policy implementations. In the following section, we provide a discussion of 
the instantiation of the Spread Chinese Policy through the four categories.

\section{Engaging with the SICP}

\section{The Context: Macro-Policy}

China's socio-economic development in recent years has motivated the government to seek more recognition on the socio-political stage of the world. Domestically, the government has scaled up its scholarships scheme for the SiCP to enhance its prestige through internationalisation of higher education. From the government's perspective, $\mathrm{SiCP}$ is a strategic move that provides a platform through education for mutual international understanding. This is stated in the Notice for the Implementation of the Administrative Rules on the Acceptance of Foreign Students by Colleges and Universities (MOE 2000):

Study in China is a cause of both practical and strategic significance. Through offering education to international students, the programme can not only help other nations develop useful talents, facilitate friendship and mutual understanding between China and other countries, but also enhance the international exchanges and cooperation of our higher education, expand its influence internationally and stimulate its development and innovation. (Translated from Chinese).

The statement reveals a twofold objective through the conjunction of 'not only'- 'but also'. It shows the value of the programme by juxtaposing the two objectives to "help other nations" and "enhance the international exchanges". While the cohesive device positions the objectives as equally important, the latter is progressive in meaning. It, thus, signals the intended meaning of the programmes: to "enhance the international exchanges and cooperation of our higher education, expand its influence internationally". Internationalisation is, thus, perceived as a form of "image planning' (Ager 2005).

To put the 'image planning' into concrete actions, the SiCP establishes that Chinese language proficiency is essential for international student education (CSC 2015), thus,

Scholarship recipients without adequate Chinese proficiency must take Chinese language courses for one to two academic years to reach the language requirements of their host universities before moving on to their major studies. Failure to reach the required language proficiency will lead to the automatic termination of scholarship. Chinese language courses are 1 year for majors in Science, Engineering, Agriculture, Medicine, Economics, Management, Legal Studies and Fine Arts, and no more than 2 years for majors in Literature, History, Philosophy and Chinese Medicine.

In the opening sentence, the scholarship recipients are 'passive agents' who 'act' on behalf of the Chinese government in promoting the status and prestige of Chinese language, as emphasised by the emotive verb 'must'. Concomitantly, 'must' is also used to establish the important role of Chinese proficiency. The adjective 'adequate' attributed to Chinese language proficiency, however, is not elaborated on with details. Following that, language proficiency is again emphasised, albeit implicitly, as one of the most important values of policy actors who will be disqualified if failing "to reach the required language proficiency". Noticeable, in the last two sentences, are the different requirements for students of science who need only 1 year before moving on to their subjects, and students of humanities who are allowed 2 years to acquire adequate Chinese proficiency. It seems that disciplines such as literature, history and Chinese Medicine are perceived as valuable cultural products deserving higher language skills. While the goals of the macro-policy are perceptible, how they are interpreted and practised by policy actors at the different levels needs to be further examined. In what follows, we look at how UoX engages with the policy.

\section{Setting: The Institutional Level of Learning Environment}

Policy interpretation is one of the most crucial aspects of policy enactment. As a sense-making process of a given policy environment, interpretation and appropriation can lead to the opening up or closing down of implementation spaces (Hornberger and Johnson 2007). The following excerpt illustrates how the UoX translates the SiCP's "international exchange" on the university webpage:

Internationalisation is one distinct trend of higher education. It is both a challenge and an opportunity for our university to raise the internationalisation level of our higher education. As an important initiator and practitioner of our university's internationalisation mission, International Education College undertakes a very import task for our university. (Translated from Chinese).

The interpretive understanding of the macro-policy to "enhance the international exchanges" and "expand its influence internationally" is to "raise internationalisation level". IEC, thus, is established as a primary conduit for 
implementing the goal. To reiterate the importance of internationalisation, the vice president of the university, $\mathrm{Mr}$ Ming, emphasises that

Education internationalisation is of top priority in the 5 year development plan of our university.

(recorded interview, 24.12.14)

As a top priority, how is internationalisation perceived? How is it interpreted and practised by policy actors? What criteria are or should be established as a standard for internationalisation? In the interview with the deputy dean of the IEC (Mr Sun), the interpretation of internationalisation is discussed:

So what motivates UoX to recruit
international students?

Sun $^{3}$ A university without international students could not be considered as a first-class university. As a university aiming at building a first-class discipline in **, an internationally first class one, how could we not have international student education? So, for our university or for any higher education, for the leaders of the university, developing international student education and at a fast speed has always been a strategically core objective for the university

(recorded interview, 21.03.15)

For the deputy Dean of IEC, international student education is a measure to indicate the status and rank of the university. In order to gain an "internationally recognised first class" reputation, "developing international student education" has been a critical strategy. Regarding how to achieve such internationalisation, the vice president of UoX, Mr Ming elaborates:

Generally speaking, for an international university, $10 \%$ of its student population should be international students. It is $10 \%$ or so for American universities. For some developed countries, the percentage even reaches $15 \%$. Of course, they have rich international student sources. What's the percentage of international students in our university? It is still rather low now. We have 26,000 students, $10 \%$ should be 2600 . There is a very large gap for us to reach that amount. We haven't even reached half of it.

(recorded interview, 24.12.14).

According to Mr Ming's interpretation, internationalisation, to the university, is to recruit $10 \%$ international

\footnotetext{
${ }^{2}$ The first author of the paper.

${ }^{3}$ All names appearing in the paper are pseudonyms. Interviews in Chinese were translated and only English translations were presented.
}

students. Comparing with universities in USA and other developed countries, he acknowledges that UoX has a "very large gap" to fill.

With the enrolment of the international students, the College, as one of its key responsibilities, has to give the students adequate language skills for them to study in China. Mr Sun believes that Chinese language programme is one of the crucial elements to achieve the goal. In a recorded interview, he reflects on the policy objective as follows:

$\mathrm{R}$ What is the objective of the Chinese language courses?

Sun It is clear, that is to improve students' Chinese use competence or their ability to master Chinese. We can't make students master Chinese-the Chinese language, characters and knowledge-in 1 to 2 years, but we can teach them how to use it as a tool. Once they have the tool, they can further Chinese learning by themselves in the future. Our objective is very clear and straightforward, that is, to improve the abilities of students' Chinese use

$\mathrm{R}$ There are many aspects of abilities, which aspect are you talking about? Their everyday use of Chinese or subject learning?

Sun We focus on two aspects; one is the fundamental one, fundamental to the discipline: the basic, disciplinary specific vocabulary in science and technology. We want students to master..., this is called basic discipline-specific Chinese. This is the first aspect. The second aspect is to improve their listening and speaking ability, that is to say, international students need to use Chinese to communicate with lecturers and students in their disciplines. Because without communication, you could not form your own understanding of the disciplinary knowledge

(recorded interview, 21.03.15)

As a prominent institutional policy actor and the mesolevel policy maker, Mr Sun plays an instrumental role in developing their institutional-level policy. He portrays IEC as a representational embodiment entrusted to undertake the responsibility of "expanding influences internationally" through language programmes. His choice of words such as "improve the abilities of students' Chinese use" and "use Chinese to communicate with lecturers and students" seems to suggest that communicative competence is a prerequisite for transferring international students to their subject study. But careful reading of his words indicates that the two aspects of Chinese language are both directed at academic competence-general academic Chinese competence and communicative academic Chinese 
competence. In his words, "basic discipline-specific vocabulary in science and technology" is "fundamental" for general academic competence. And "to use Chinese to communicate with lecturers and students in their disciplines" requires the communicative competence of academic Chinese to function in disciplinary learning.

The above expressed accounts demonstrate the interpretative process of policy enactment at the management level. While setting up clear goals for the university, how these goals and objectives are further interpreted and translated into classroom teaching will lead to our investigation on what takes place in the actual classroom and what resources are available to support international students' Chinese learning.

\section{Situated Activities: Teaching and Learning Chinese in Classrooms}

The international students at UoX came from different countries, possessed different levels of Chinese proficiency, and were pursuing different degrees and studying different subjects. Since most students are science and engineering majors, the required Chinese language preparatory period is 1 year. The Chinese preparatory programme prepares students to work on all four language skills. But elective courses are also available to introduce Chinese culture, such as Chinese Calligraphy and Martial Arts. During our field work semester, there were 110 students registered for the preparatory courses, 90 chose the three beginning-level classes and only 20 registered for an intermediate level.

\section{Teaching Materials}

How to prepare the students for smoothly transferring to academic study in Chinese medium programmes presented obvious challenges as reflected in the teaching materials. The adopted Chinese textbook series is Developing Chinese (Beijing Language and Culture University Press), which includes four components: Comprehensive Chinese, Speaking, Listening, Chinese Characters Reading and Writing. Each component has six books, for beginners, intermediate and advanced learners, respectively. Table 1 provides a list of the contents in the Comprehensive Chinese series.

The list of contents indicates that the purpose of the preparatory programme is to integrate international students into Chinese society and social life. Topics in the beginners' series are mostly centred on studying and living in China, whereas the intermediate series contain primarily essay-like articles introducing the life and culture of Chinese people. Most conversations, texts and exercises are contrived sentences designed for practising the target grammar forms such as "......" (one does something whenever he/she feels like it). The vocabulary and linguistic skills required for the programme focus predominantly on everyday communicative needs, not on academic communicative competence.

\section{Classroom Observation}

Our observations of both the elementary and intermediate language classes reveal that the classes are heavily textbookbased. It is usually around the topic listed in each unit of the textbook, including a series of Chinese reading, listening, speaking or writing activities as well as various vocabulary exercises and pattern drills. In line with the textbooks, the Chinese classes also centre on developing general communicative Chinese competence. There is little evidence that the learning Chinese is for academic purposes or oriented towards subject specifics (Field note, 14.01.15).

The Chinese lecturers interviewed acknowledge that the Chinese courses aim to teach international students "basic Chinese knowledge" (Interview with CLL-T2; 25.11.14) and "everyday Chinese expressions ... such as how to introduce oneself, how to communicate with shop assistants, how to order food, etc". (Interview with CLL-T3;

Table 1 Topics discussed in elementary and intermediate Chinese textbooks

\begin{tabular}{|c|c|}
\hline Elementary comprehensive Chinese & Intermediate comprehensive Chinese \\
\hline 1. Hello & 1. Four seasons of Beijing \\
\hline 2. Which country are you from? & 2. There is only one requirement for renting a room \\
\hline$\cdots$ & $\cdots$ \\
\hline 7. Where is the Bank of China & 7. I learn "generosity" in China \\
\hline 9. What's your plan for today & $\ldots$ \\
\hline$\ldots$ & 10. Add some salt to coffee \\
\hline 14. I bought a sweater & 11. The pleasures and troubles of the SOHO group \\
\hline 15. Can college students have part-time jobs & $\ldots$ \\
\hline$\ldots$ & 13. The three most important things in life \\
\hline 30. I used to be an English teacher & $\ldots$ \\
\hline
\end{tabular}


13.01.15). They further confirm that the degree students are allowed 1 year to learn Chinese before being transferred to normal academic setting. As expressed by Jing (CLL-T4):

The single year meant only to teach them basic Chinese language skills. You know, most of the students have no Chinese learning experiences before coming to China.

(recorded interview, 20.01.15)

Shan (CLL-T5) adds:

We hope that once the students acquire the basic knowledge of Chinese, they would gradually develop academic Chinese competence in the process of academic learning.

(recorded interview, 22.01.15).

The acknowledgements about the Chinese preparatory programme seem to support the institutional policy expressed by Mr Sun. While the interpretation of meso-policy by these lecturers is closely observed, another policy environment has impacted on their decision-making process about what and how to teach. Lecturer You (CLL-T1) points out that they have to teach for the high-stake HSK tests,

Actually, their HSK test results determine whether they can be upgraded to academic learning and also whether they can continually enjoy the Chinese government scholarships.

(recorded interview, 27.12.14).

But the Syllabus of HSK clearly specifies that HSK is "an international standardised test that examines international Chinese learners' basic (or general) Chinese language proficiency". There is no requirement for academic Chinese competence in HSK $3 \& 4$, the required levels for academic studies (Hanban 2010, p. 4).

Test takers who are able to pass HSK 3 can communicate in Chinese at a basic level in their daily, academic and professional lives. They can manage most communication in Chinese when travelling in China. Test takers who are able to pass HSK 4 can converse in Chinese on a wide range of topics and are able to communicate fluently with native Chinese speakers.

Taking the different levels of policy contexts into consideration, the Chinese language lecturers develop their own teaching decisions in the language preparatory courses as teaching students basic knowledge of Chinese for general communicative purpose. The difference between academic language skills and general communicative competence, however, is vast. The former is known as decontextualised language; it goes with cognitive development and determines the success of academic learning (Cummins 2008). The latter is a context-embedded communicative language skill. These lecturers' perceptions raised an implicit misalignment between the goals of the University as represented by the management and the reality of teaching voiced by the lecturers.

\section{Self: Personal Experiences}

With regard to international students' personal experiences, two themes emerge: the competing role of English and Chinese and issues of academic language.

The Competing Role of English versus Chinese for International Students

Despite the intensification of the SiCP under the current Chinese language promotion policy, English is found to be an oft-used language for international students in everyday communication. Lynda, a year three student from Madagascar, comments on her 'poor' Chinese proficiency despite her 3 years studying in China.

Lynda Yeah, I don't speak Chinese every day, so it's very hard for me

$\mathrm{R} \quad$ Why do you not find opportunities to speak Chinese, you're in China

Lynda Because I don't have more Chinese friends. I really got some, some Chinese friends, but they want to learn English, and I want to learn Chinese

R So?

Lynda I want to speak Chinese to them, but they want to speak English to me

$\mathrm{R} \quad$ Why don't you tell them directly that you want to practise Chinese, you can speak English for half of the time, and Chinese for another half

Lynda They just speak English, I tried a number of times, then gave up

(recorded interview, 17.12.14)

Lynda's complain is particular illuminative of the tension between English and Chinese as the lingua franca on campus. The promotion of English in China in recent years has created a pro-English discourse among Chinese students (Shao and Gao 2016; Wang 2015). When approached by international students, Chinese students tend to use English because of their few opportunities to practise English. This conflicts with the goal of current Chinese policy where international students should be fully immersed in Chinese environment. Although students like Lynda have transferred to their academic programmes, there are few communicative opportunities in classroom as academic courses tend to be teacher-denominated. 
The policy decision at the Chinese preparatory level also shows the power imbalance of the two languages. While both administrators and the Chinese lecturers confirm that they use Chinese as much as possible to immerse international students in a Chinese environment to facilitate their Chinese acquisition, our observation of the 16 sessions of language classroom shows that English was frequently used. Lecturers rely heavily on English to organise class and explain Chinese usages to students (Field note, 02.12.14).

Outside classrooms, English has also become the lingua franca among international students. While many come to China with the assumption that they would be naturally immersed in a Chinese environment by living and studying in China, in reality the separate accommodation has prevented them from socialising with their Chinese counterparts. When forming their own community, English instead of Chinese becomes the common language of communication.

The perception of Chinese and English by different student groups has led to a serious dislocation between international and Chinese students. Consequently, the international students tend to form their own groups and stay away from the Chinese students, thus having little exposure to Chinese language. Given their different linguistic backgrounds and their not-that-good Chinese, it is more often English than Chinese that serves as the lingua franca among the international students and between international and Chinese students.

\section{Learning BICS, Demanding CALP}

In our discussion of the institutional settings and situated activities, we have demonstrated that the institutional goals (CALP) and the preparatory course objective (BICS) differ. The differences have also been experienced by the students. Having been in China for five years, Tamer (DSLS7) expresses his frustration in the following interview:

Tamer ... but quite a lot of Chinese, we do not understand. In class, if the teacher speaks Chinese, we cannot understand; because the teacher speaks too fast. Most students in the class are Chinese. There are only we four international students. So the teacher says that he cannot speak slowly...

$\mathrm{R}$ Altogether, how many years have you studied Chinese?

Tamer One and half years. In fact, it is not enough even for 2 or 3 years. This is a huge problem for us. A lecturer asked us whether I could understand. I said no. Then he questioned me why I stayed in China; why don't you study Chinese seriously. I told him that I learned how to go shopping, how to see a doctor when I have a stomach pain, how to order food when hungry. These are what I have learned. Nothing else

$\mathrm{R} \quad$ The Chinese you have learned is only for everyday communication, but not for subject learning, isn't it?

Tamer Yes

$\mathrm{R} \quad$ Did you tell your professors about this?

Tamer He said he had nothing to do about this. He could not teach, we few international students, Chinese in disciplinary courses

$\mathrm{R}$ Then what do you do? How do you solve the problem?

Tamer After class, we go home and check the content of the course, then I look for the content in Arabic. I learn the content in Arabic. That's it

(recorded interview, 25.03.15)

Tamer's experience provides a strong contrast between CALP required for academic learning and BICS taught at the institute. Cummins (2008) maintains that although the two types of competence are interconnected, the mastering of one does not necessarily lead to the achievement of the other. While academic language proficiency is indispensable for academic learning, it is difficult to attain and takes years to master. The language preparatory courses, as expressed by Tamer, provide only 1 year of general Chinese learning where he "learned how to go shopping, how to see a doctor when I have a stomach pain, how to order food when hungry". The mismatch between what they have learnt in language preparatory courses and what is actually required for academic study presents a serious challenge. All eight degree students interviewed agree that studying academic courses in Chinese is challenging and the oneyear language preparation is far less than sufficient, although they admit that the Chinese language courses are effective for the learning of everyday Chinese.

Tamer's frustration has also been reflected in his professor's reaction to his insufficient academic Chinese-_ "He said he had nothing to do about this. He could not teach we few international students Chinese in disciplinary courses". Our interviews with faculty professors indicate that they recognise international students' language difficulties but tend to leave the problem to the IEC. One professor, Neng (DSL-T3), in Geology recounts his experiences with an international student in his course.

You see, these international students come to study in Chinese universities. They still have problems in Chinese, how could they study subject courses, particularly these highly specialized courses. Like mine, it involves too many terminologies and jargons. 
Without any background of academic Chinese in the discipline, can you imagine how difficult it is. For them? There was one in my course. When the final exam approached, he came to my office every day and pleaded for a pass. He frankly told me that he could not understand the lectures and could not read the textbook in Chinese. What should I do? You tell me. I could not stop the lecture to teach him Chinese in class, right? But he also shouldn't be blamed. All in all, he has only learned Chinese for one year. You could not expect too much. Think of our own students. They have learned English for nearly 10 years, but still rather poor in English. So the only thing I could do was to help him prepare for the exam.

(recorded interview, 18.11.14)

In this conversation, Neng raises an alarming issue about international students' language ability and proficiency in their academic programme. Framing his concern in the context of exam, he questions indirectly the validity of internationalisation. Helping the student pass the exam is "the only thing I could do". The way in which international students are integrated into the Chinese way of life for Chinese learning and the need of learning Chinese for academic purposes place lecturers and students in difficult positions.

\section{Discussion: Tensions and Dilemmas}

Our inquiry has covered four dimensions of the SiCP at the UoX. The results indicate that despite the government's well-envisioned plan, the realities in actual implementation present a series of challenges. Through our investigation at different policy implementation levels with the institutional management, lecturers teaching language and academic subjects and international students, three major conflicts surfaced: the government and the institution have divergent goals of internationalisation; language for academic purpose versus language for basic interpersonal communication and the competing role of Chinese versus English.

Firstly, the government and the institution have divergent goals of internationalisation. Our examination of the policy texts from both the government and the university indicates that although both polities aim to achieve internationalisation through the $\mathrm{SiCP}$, they have different goals and expectations. While the government sets its objective to "enhance the international exchanges" and to "expand its influence internationally", the university aims to raise its international reputation by increasing enrolment. As a language spread strategy, the government emphasises cultural diffusion using language courses to enhance the appreciation of both linguistically and non-linguistically related cultural products. The university, however, is more interested in its international status in higher education, thus, aiming to increase its population diversity by attracting international students. The different goals, thus, require different measures. From the government's perspective, Chinese language is a vehicle for accessing cultural products, which requires individuals to have a thorough grasp of the 'cultural-communicative' language. The university, on the other hand, needs to equip international students with a solid academic language to study academic subjects. Consequently, the conflicting goals lead to a series of challenges in policy enactment causing tensions between policy actors.

Secondly, the actual offer of Chinese for basic interpersonal communication mismatches with the need of Chinese for academic purpose. The tension is clearly evidenced by the frustrations of academic lecturers and students with each other. While the lecturers feel helpless with the students' inadequate academic progress because of their insufficient academic language, the students feel despair about their preparatory language courses. As the oneyear course focuses mainly on general communicative language skills, the students have hardly any opportunities to develop the academic language skills needed for accessing cognitively demanding academic studies. This has forced faculties and students to compromise their academic studies.

The last tension was the competing role of English versus Chinese on campus. Our data indicate that despite Chinese being the language of communication in the wider community and the medium of instruction, international students have limited opportunities to engage in language practices with local students, partly because they live in an isolated compound and partly because the Chinese students want to speak English. The data show that the international prestige of English has not only spread outside China but also established its position in China, even within the confines of UoX.

\section{Conclusion}

Our inquiry has presented an on-going study of the recent enactment of The International Chinese Promotion Policy. Drawing on ethnography of language policy, our study has explored issues of teaching and learning Chinese at different levels of policy creation, interpretation and appropriation. By examining policy objectives between the government and the university, our study shows that mesolevel of policy interpretation is conditioned by the institution's understanding of internationalisation, thus, engendered competing intentions and different goals established between the macro- and meso-policy makers. 
At the micro-level, our study reveals that although international students' recognition of Chinese language has the potential to spread Chinese language and culture, the challenging academic programme and separate living environments have been prohibiting the implementation of Study in China Policy. The conflicting interests of social actors at national, institutional and individual levels cause considerable conflicts and tensions which greatly reduce international students' benefits from studying in China and also render the well-envisioned objectives of the SiCP difficult to achieve.

Our study has contributed to the theory of 'ethnography of language policy' by looking at the interpretive processes of the International Chinese Promotion Policy carried out by different policy actors across multiple layers of creation and appropriation-institutional administrator, lecturers and students. Like studies on the negotiation of language policy in schools (Menken and García 2010), slicing the policy onions by Hornberger and Johnson (2007), and summary of ethnographic policy investigations in different socio-political contexts (Johnson 2013), our inquiry has made connections between the macro, meso and micro to illuminate the complexity of policy implementation.

Methodologically, our study has contributed to the field of LPP by demonstrating how agents such as administrators and lecturers; contexts such as institutions and classrooms and processes such as teaching materials and classroom interactions, can "open up or close down of ideological and implementational spaces" (Hornberger and Johnson 2007, p. 509) for Chinese language Promotion.

Acknowledgments The project is supported by the University Funding for Outstanding Young Researchers in China University of Geosciences (No. CUG160213).

Open Access This article is distributed under the terms of the Creative Commons Attribution 4.0 International License (http:// creativecommons.org/licenses/by/4.0/), which permits unrestricted use, distribution, and reproduction in any medium, provided you give appropriate credit to the original author(s) and the source, provide a link to the Creative Commons license, and indicate if changes were made.

\section{Appendix}

Appendix I The Chinese language and subject courses observed

\begin{tabular}{|c|c|c|c|c|c|}
\hline \multicolumn{2}{|l|}{ Chinese Language Courses } & Teacher & Alias & Sessions* & Date \\
\hline \multicolumn{2}{|c|}{ Intermediate Comprehensive Chinese } & CLL-T1 & You & 4 & $26 / 11 / 2014$ \\
\hline \multicolumn{2}{|c|}{ Intermediate Comprehensive Chinese } & CLL-T1 & You & 4 & $01 / 12 / 2014$ \\
\hline \multicolumn{2}{|c|}{ Elementary Comprehensive Chinese } & CLL-T2 & $\mathrm{Yu}$ & 4 & $25 / 11 / 2014$ \\
\hline \multicolumn{2}{|l|}{ Elementary Chinese Speaking } & CLL-T3 & Xia & 4 & $02 / 12 / 2014$ \\
\hline \multicolumn{2}{|l|}{ Elementary Chinese Listening } & CLL-T5 & Shan & 4 & $14 / 01 / 2015$ \\
\hline \multicolumn{2}{|c|}{ Elementary Chinese Characters Reading and Writing } & CLL-T4 & Jing & 4 & $24 / 12 / 2014$ \\
\hline Disciplinary Subject Courses & Teacher & & & Sessions & Date \\
\hline Human Resources & DSL-T1 & & & 4 & $17 / 12 / 2014$ \\
\hline Engineering Geology & DSL-T2 & & & 2 & $23 / 12 / 2014$ \\
\hline Metamorphic Petrology & DSL-T3 & & & 2 & $18 / 11 / 2014$ \\
\hline
\end{tabular}

$*$ One session $=45 \mathrm{~min}$ 


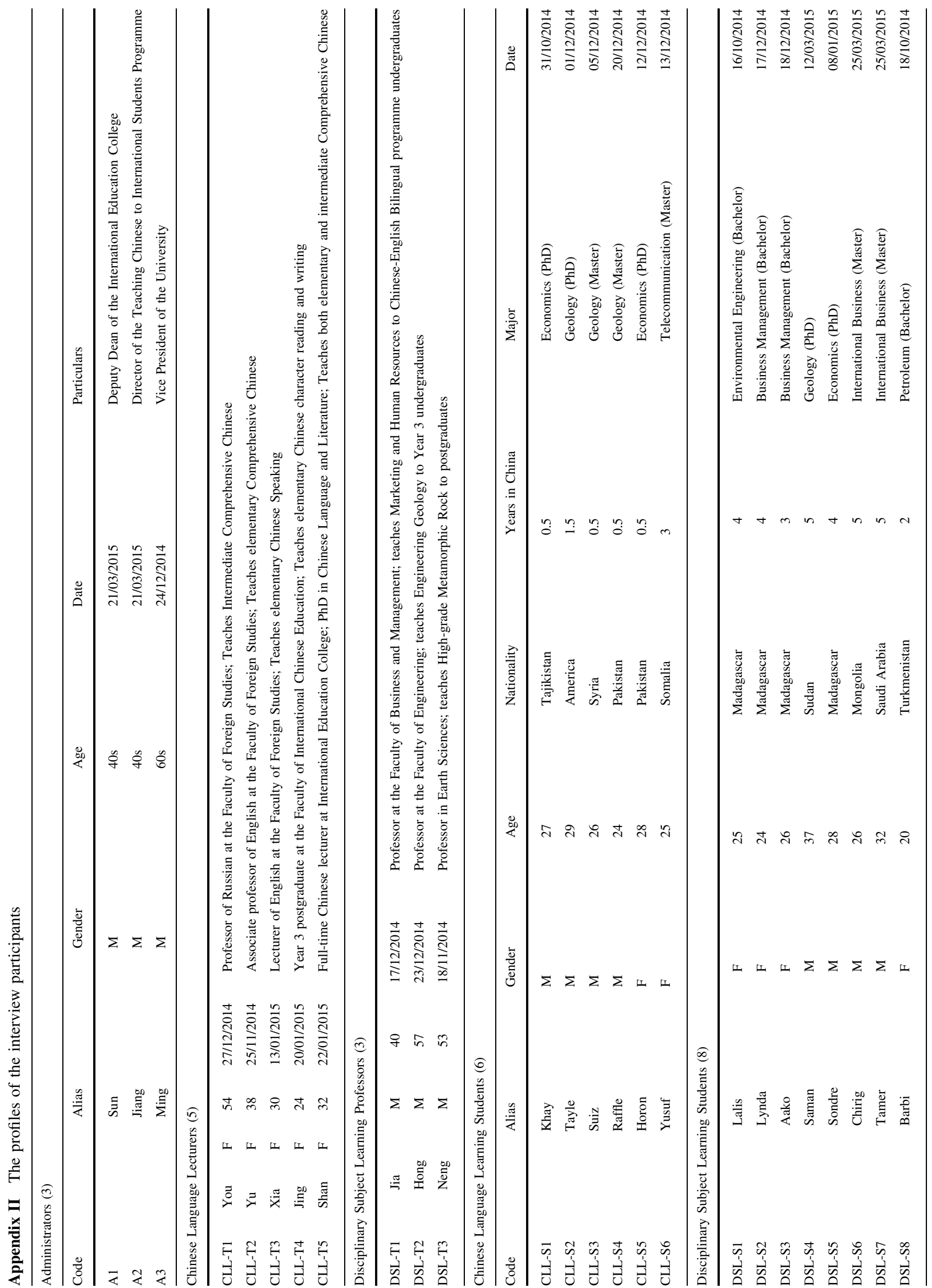




\section{References}

Ager, D. (2005). Image and Prestige Planning. Current Issues in Language Planning, 6(1), 1-43.

CSC (Chinese Scholarship Council). (2015). Introduction to Chinese Government Scholarships. Retrieved from http://www.csc.edu. $\mathrm{cn} /$ Laihua/scholarshipdetailen.aspx cid= $=97 \& \mathrm{id}=2070$.

Cui, X. (2010). The development and prospect of teaching Chinese as a second language and international Chinese education [Duiwaihanyu jiaoxue yu hanyu guojijiaoyu de fazhan yu zhanR]. Applied Linguistics [Yuyan Wenzi Yunyong], 2, 2-11.

Cummins, J. (2008). BICS and CALP: Empirical and theoretical status of the distinction. In B. Street \& N. H. Hornberger (Eds.), Encyclopedia of language and education: Literacy (pp. 71-83). New York: Springer.

Curdt-Christiansen, X. L., \& Hancock, A. (Eds.). (2014). Learning Chinese in diasporic communities: Many pathways to being Chinese. Amsterdam: John Benjamins.

Dong, L., \& Chapman, D. W. (2008). The Chinese government scholarship program: An effective form of foreign assistance? International Review of Education, 54(2), 155-173.

Fallon, T. (2014). Chinese fever and cool heads: Confucius Institutes and China's national identities. China Media Research, 10(1), $35-47$.

Hanban. (2010). New syllabus of HSK. Shanghai: The Commercial Press.

Haugen, H. Ø. (2013). China's recruitment of African university students: policy efficacy and unintended outcomes. Globalisation, Societies and Education, 11(3), 315-334.

Hornberger, N. H., \& Johnson, D. C. (2007). Slicing the onion ethnographically: Layers and spaces in multilingual language education policy and practice. TESOL Quarterly, 41(3), 509532

Johnson, D. C. (2013). Language policy. Basingstoke, UK: Palgrave Macmillan.
Li, X. (2015). International students in China: Cross-cultural interaction, integration, and identity construction. Journal of Language, Identity \& Education, 14(4), 237-254.

Menken, K., \& García, O. (Eds.). (2010). Negotiating language policies in schools: Educators as policymakers. New York: Routledge.

MOE. (2000). A Notice for the Implementation of the Administrative Rules on the Acceptance of Foreign Students by Colleges and Universities. Retrieved from http://www.moe.edu.cn/publicfiles/ business/htmlfiles/moe/moe_861/200506/8653.html.

MOE. (2010a). National Outline for Medium and Long-term Education Reform and Development (2010-2020). Retrieved from http://www.moe.gov.cn/srcsite/A01/s7048/201007/t20100729 171904.html.

MOE. (2010b). MOE Announcement of the Study in China Plan. Retrieved March 1, 2016, from http://www.moe.gov.cn/srcsite/ A20/moe_850/201009/t20100921_108815.html.

MOE. (2016). Statistics of international students in China in 2016. Retrieved March 1, 2016, from http://www.moe.gov.cn/ jyb_xwfb/gzdt_gzdt/s5987/201604/t20160414_238263.html.

Paradise, J. F. (2009). China and international harmony: The role of Confucius Institutes in bolstering Beijing's soft power. Asian Survey, 49(4), 647-669.

Schweller, R. L., \& Pu, X. (2011). After unipolarity: China's visions of international order in an era of US decline. International Security, 36(1), 41-72.

Shao, Q., \& Gao, X. (2016 First View). Noisy guests shall not unseat the host. English Today. doi:10.1017/S0266078416000419.

Tsung, L., \& Cruickshank, K. (Eds.). (2011). Teaching and learning Chinese in global contexts: CFL worldwide. London: Continuum.

Wang, W. (2015). Teaching English as an international language in China: Investigating university teachers' and students' attitudes towards China English. System, 53, 60-72. 